\title{
VARIAÇÕES DE MASSA E DE NITROGÊNIO EM CARNE SUÍNA APÓS DESCONGELAMENTO
}

\author{
GILBERTO COSTA BRAGA* \\ JOCÉLIO DOS SANTOS ARAUJO** \\ REGINA CONCEIÇÃO GARCIA** \\ ELEANDRO APARECIDO RIZZO*** \\ OSSIVAL LOLATO RIBEIRO***
}

\begin{abstract}
Objetivou-se neste trabalho avaliar a qualidade físicoquímica de carne suína durante o descongelamento, mediante determinação das variações de massa e de nitrogênio por exsudação (gotejamento). Amostras de $300 \mathrm{~g}$ de carne de lombo suíno das raças Landrace, Large White e Piau foram congeladas e depois submetidas ao descongelamento lento. As avaliações das amostras das três raças ocorreram em três tempos de descongelamento (6, 12 e 24 horas). A carne da raça Piau evidenciou a menor perda de massa por gotejamento e a da raça Landrace revelou maior perda de massa até 12 horas de descongelamento. A raça não exerceu efeito sobre o teor de nitrogênio total contido nos exsudados dos lombos nos três períodos avaliados. No entanto, houve elevação significativa na concentração de nitrogênio do exsudado com o aumento do tempo de descongelamento para as três raças estudadas.
\end{abstract}

PALAVRAS-CHAVE: CARNE SUÍNA - CONGELAMENTO; RETENÇÃO DE ÁGUA.

\section{INTRODUÇÃO}

No início da década de 80, a expansão de grandes redes de supermercados e a consolidação do auto-serviço nos setores de açougue dessas redes alteraram os hábitos de compra de carnes. Uma das

* $\quad$ Professor, Doutor em Tecnologia de Alimentos, Centro de Ciências Agrárias (CCA), Universidade Estadual do Oeste do Paraná (UNIOESTE), Marechal Cândido Rondon, Cx.P. 1008, 85960-000 PR (e-mail: gbraga@unioeste.br).

** Professor, Doutor em Zootecnia, CCA-UNIOESTE, Marechal Cândido Rondon, PR.

*** Graduandos do Curso de Zootecnia, CCA-UNIOESTE, Marechal Cândido Rondon, PR. 
principais mudanças foi a introdução de programas de Garantia de Qualidade (Quality Assurance Schemes) na indústria de carne e em seus diversos seguimentos, tendo como meta abranger todos os aspectos de qualidade que são importantes para o consumidor (WOOD, HOLDER e MAIN, 1998).

Diversas formas de tratamento pós-abate das carcaças são utilizadas pelas indústrias com a finalidade de diminuir e/ou eliminar os desvios de qualidade na transformação de músculo em carne. Dentre esses, o mais comum é o uso de baixas temperaturas (PARDI et al., 1995). O congelamento constitui excelente método de conservação da carne fresca, porque as alterações são mínimas durante o armazenamento congelado (COLLIN, 1977).

Sob o ponto de vista nutricional, a presença da carne na dieta humana representa fonte de proteínas com alto valor biológico, ferro e vitaminas do complexo B (PARDI et al., 1995). Entretanto, seu valor nutritivo pode ser alterado durante as etapas de congelamento, descongelamento e cortes (conhecidas como operações de pré-preparo). As carnes perdem expressivas quantidades de exsudado, que podem carrear diversos nutrientes hidrossolúveis e resultar em redução de massa das carnes (CHEFTEL, CUQ e LORIENT, 1989).

Dentre as propriedades funcionais apresentadas pelas proteínas musculares das carnes, a capacidade de retenção da água (CRA) destaca-se por determinar vários atributos após a etapa de preparo. A CRA está relacionada com vários atributos de ordem sensorial (PARDI et al., 1995).

A desnaturação de proteínas miofibrilares, que ocorre durante o armazenamento congelado, pode provocar diminuição na retenção de água das carnes (SGARBIERI, 1996). Essa propriedade envolve a capacidade da carne em reter sua própria água durante a aplicação de forças externas como cortes, aquecimento, trituração e prensagem (JUDGE et al., 1989). Maior CRA aumenta a suculência da carne e a percepção sensorial de maciez, influenciando seu valor econômico e nutricional. A diminuição da CRA por exsudação ocasiona prejuízos, gerando menor rentabilidade, além de acarretar perdas de nutrientes hidrossolúveis (como proteínas, peptídeos, aminoácidos, ácido lático, purina, vitaminas do complexo B e outros elementos) (CHEFTEL, CUQ e LORIENT, 1986). 
As proteínas miofibrilares respondem por $75 \%$ da CRA (JUDGE et al., 1989). Cerca de $70 \%$ de toda a água presente na carne fresca localizase entre as miofibrilas (espaços interfibrilares do tecido muscular), $20 \%$ no sarcoplasma e $10 \%$ no tecido conjuntivo. A desnaturação das proteínas miofibrilares pode ocorrer pela aplicação de calor ou de frio (congelamento), interferindo na capacidade de retenção da água (SHENOUDA, 1980; SGARBIERI, 1996).

Nas etapas de congelamento e descongelamento as perdas de nutrientes e de massa por exsudação são bastante significativas, e se refletem negativamente nos atributos de suculência, maciez, cor e sabor da carne. Tal fato influencia sua aceitação pelos consumidores, pois essas características sensoriais são muito relevantes na avaliação final do produto (PIRES et al., 2002). A velocidade com que as carnes são congeladas e descongeladas também interfere na CRA, sendo as técnicas de congelamento rápido e de descongelamento lento as mais indicadas para maior retenção de água (HONIKEL e HAMM, 1985).

Segundo ARAÚJO (1995) variações no pH da carne influenciam a sua CRA, ou seja, a formação de ácido lático e a conseqüente queda do pH post-mortem são responsáveis pela diminuição da capacidade de retenção de água da carne. Tal efeito decorre da neutralização das cargas dos grupos hidrofílicos das proteínas miofibrilares e a conseqüente incapacidade de atrair água, sendo denominado de efeito de carga neutra. A capacidade de retenção de água é menor em pH 5,2-5,3, ou seja, no ponto isoelétrico $(\mathrm{pl})$ da maior parte das proteínas musculares. A influência do $\mathrm{pH}$ também é verificada em carnes de animais susceptíveis ao estresse, denominadas carnes pálidas, macias e exsudativas (em inglês - pale, soft, exsudative-PSE). Quando em condições estressantes, os animais apresentam sistemas circulatório e respiratório deficientes, cujas reservas mínimas de oxigênio se esgotam rapidamente após 0 abate. $O$ músculo recorre ao mecanismo anaeróbio para a obtenção de energia, ocasionando queda no $\mathrm{pH}$ muscular que associada com altas temperaturas provoca a desnaturação das proteínas miofibrilares. A CRA não se altera em carnes de animais resistentes ao estresse, denominadas escura, firme e seca (em inglês - dark, firm and dry - DFD), pois o pH situa-se próximo ao ponto fisiológico e as proteínas permanecem intactas.

A variação da qualidade da carne suína encontrada após o resfriamento das carcaças tem como referencial a carne ideal, identificada em inglês como Reddish Pink, Firm and Not Exudative (RFN). As alterações de qualidade incluem as carnes PSE (Pale, Soft and Exudative), RFN 
(Reddish, Pink, Soft and Exudative) e DFD (Dark, Firm and Dry) (PARDI et al., 1995). Segundo JUDGE et al. (1989), as carnes PSE representam o problema mais sério para a indústria pela perda excessiva de exsudado, textura muito flácida e ausência de cor. Além de serem rejeitadas pelos consumidores, prejudicam os processos industriais de fabricação com conseqüências econômicas bastante sérias para o setor. PELOSO (2003) relatou que os desvios de qualidade que ocorrem na carne suína são causados ao mesmo tempo por fatores ambientais e genéticos.

O Brasil é produtor de suínos de raças importadas (exógenas) como Large White e Landrace, sendo que algumas linhagens da raça Landrace podem apresentar carne PSE. As raças nacionais, importantes para a suinocultura de subsistência, têm na raça Piau uma das principais representantes, cujas características incluem alta rusticidade e baixo rendimento/qualidade de carcaça (LOVATTTO e OLIVEIRA, 1996).

O objetivo deste trabalho foi avaliar a qualidade físico-química da carne suína durante o descongelamento, mediante determinação das perdas de massa e de nitrogênio por exsudação (gotejamento).

\section{MATERIAL E MÉTODOS}

O experimento foi conduzido nos laboratórios de Tecnologia de Alimentos e de Química Agrícola e Ambiental do Centro de Ciências Agrárias da Universidade Estadual do Oeste do Paraná (UNIOESTE), campus de Marechal Cândido Rondon, PR.

Amostras de $300 \mathrm{~g}$ de carne de lombo suíno (longissimus dorsi) das raças Landrace, Large White e Piau foram acondicionadas em bandejas de isopor, embaladas em filme plástico de policloreto de vinila (PVC) e congeladas em freezer a $-18^{\circ} \mathrm{C}$. Os pesos de abate dos animais foram de aproximadamente $90 \mathrm{~kg}$. As amostras de carnes ficaram 15 dias sob congelamento, quando foram efetuados os tratamentos de descongelamento para o estudo.

As análises foram realizadas em três períodos de descongelamento das carnes (6, 12 e 24 horas), após os quais foram coletadas amostras de exsudado para as determinações de variação de massa das carnes e de nitrogênio dos fluídos exsudados. O descongelamento lento das amostras de carne ocorreu sob temperatura de aproximadamente $5^{\circ} \mathrm{C}$ em câmara refrigerada. 
A variação de massa das amostras de lombo suíno foi determinada pela diferença de pesos, verificada antes do congelamento e depois do descongelamento. As pesagens foram realizadas em balança digital semianalítica marca Marte, modelo AS5500C.

A variação de nitrogênio total nos fluidos exsudados foi determinada após os períodos de descongelamento, utilizando-se o método adaptado de Kjeldhal, segundo CECCHI (1999). Esse método baseia-se na transformação do nitrogênio da amostra em sal amoniacal por meio de digestão ácida e determinação do nitrogênio total por titulação.

Aplicou-se delineamento inteiramente ao acaso em esquema fatorial $3 \times 3$, ou seja, três níveis do fator tempo de descongelamento e três níveis do fator raça suína, com três repetições por tratamento, conforme BANZATTO e KRONKA (1995).

\section{RESULTADOS E DISCUSSÃO}

A carne da raça Piau apresentou a menor perda de massa por gotejamento após os três períodos de congelamento avaliados (Tabela 1). Os lombos das três raças apresentaram os maiores índices de perda de massa entre 6 até 12 horas de descongelamento, provavelmente, por estarem praticamente descongelados após 12 horas sob temperatura de $5^{\circ} \mathrm{C}$.

As menores perdas de massa verificadas até o período de 6 horas (Tabela 1) ocorreram pelo fato das amostras de lombo ainda estarem congeladas, ou em início de descongelamento (maioria dos cristais de gelo ainda estava formada). $\mathrm{O}$ ambiente refrigerado $\left(\mathrm{a}^{\circ} \mathrm{\circ}\right)$ ) deve ter retardado $\mathrm{o}$ início do descongelamento, atingindo o máximo em 12 horas quando as perdas de fluidos por exsudação foram maiores.

Verificou-se (Tabela 1) que o lombo da raça Landrace apresentou maior perda de massa $(p \leq 0,05)$ até 12 horas de descongelamento. Conforme relataram JUDGE et al. (1989), a capacidade de retenção de água nas carnes está associada com as proteínas miofibrilares e qualquer condição que as afete pode interferir na CRA. Para LEANDER (1980) os principais fatores envolvidos na CRA são o pH, o estado de contração muscular e a desnaturação das proteínas miofibrilares. Assim, menor índice de retenção de água na carne do lombo da raça Landrace (Tabela 1) pode estar relacionado com maior índice de desnaturação de proteínas causada pela formação de cristais de gelo durante o congelamento. Segundo 
SHENOUDA (1980) e SGARBIERI (1996) o congelamento ou o armazenamento da carne congelada pode causar desnaturação das proteínas miofibrilares, alterando os espaços interfibrilares do tecido muscular e diminuindo a capacidade de retenção de água. FENNEMA (1993) relatou, também, que a desnaturação das proteínas da carne é responsável por mudanças em sua estrutura e carga, acarretando diminuição da retenção de água.

\section{TABELA 1 - PERDAS DE MASSA (\%) DOS LOMBOS SUÍNOS EM FUNÇÃO DO TEMPO DE DESCONGELAMENTO E DA RAÇA}

\begin{tabular}{c|c|c|c|c}
\hline \multirow{2}{*}{ Raça } & \multicolumn{3}{|c|}{ Tempo de descongelamento (horas) } & \multirow{2}{*}{ Total } \\
\cline { 2 - 4 } & $\mathbf{6}$ & $\mathbf{1 2}$ & $\mathbf{2 4}$ & \\
\hline Piau & $0,38 \mathrm{a} \mathrm{A}$ & $2,03 \mathrm{a} \mathrm{B}$ & $1,72 \mathrm{a} \mathrm{B}$ & $4,13 \mathrm{a}$ \\
Large White & $0,46 \mathrm{a}$ A & $2,92 \mathrm{a} \mathrm{B}$ & $2,71 \mathrm{a} \mathrm{B}$ & $6,09 \mathrm{~b}$ \\
Landrace & $0,33 \mathrm{a} \mathrm{A}$ & $4,56 \mathrm{~b} \mathrm{~B}$ & $2,37 \mathrm{a} \mathrm{C}$ & $7,26 \mathrm{~b}$ \\
\hline
\end{tabular}

Médias seguidas pela mesma letra minúscula na coluna não diferem estatisticamente em nível de $5 \%$ pelo teste de Tukey.

Médias seguidas pela mesma letra maiúscula na linha não diferem estatisticamente em nível de $5 \%$ pelo teste de Tukey.

Não foi verificado efeito significativo $(p>0,05)$ da raça sobre o teor de nitrogênio total contido nos exsudados dos lombos após os três períodos avaliados (Tabela 2). Porém, houve aumento significativo $(p \leq 0,05)$ na concentração de nitrogênio do exsudado com o maior tempo de descongelamento para as três raças estudadas. Tal fato foi acompanhado pelo aumento no volume de massa exsudada até o período de 12 horas (Tabela 1), quando a carne já deveria ter atingido o descongelamento total. Porém essa correlação foi inversa entre os períodos de 12 e 24 horas, indicando maior índice de perda de nitrogênio por unidade de massa exsudada após o descongelamento do que durante o mesmo.

\section{TABELA 2 - TEORES DE NITROGÊNIO (\%) NOS EXSUDADOS DOS LOMBOS SUÍNOS EM FUNÇÃO DO TEMPO DE DESCONGELAMENTO E DA RAÇA}

\begin{tabular}{c|ccc|c}
\hline \multirow{2}{*}{ Raça } & \multicolumn{3}{|c|}{ Tempo de descongelamento (horas) } & \multirow{2}{*}{ Total } \\
\cline { 2 - 4 } & $\mathbf{6}$ & $\mathbf{1 2}$ & $\mathbf{2 4}$ & \\
\hline Landrace & $1,92 \mathrm{a} \mathrm{A}$ & $2,64 \mathrm{a} \mathrm{B}$ & $3,38 \mathrm{a} \mathrm{C}$ & $2,85 \mathrm{a}$ \\
Large White & $2,14 \mathrm{a} \mathrm{A}$ & $2,81 \mathrm{a} \mathrm{B}$ & $3,37 \mathrm{a} \mathrm{B}$ & $3,01 \mathrm{a}$ \\
Piau & $2,39 \mathrm{a} \mathrm{A}$ & $2,97 \mathrm{a} \mathrm{AB}$ & $3,43 \mathrm{a} \mathrm{B}$ & $3,11 \mathrm{a}$ \\
\hline
\end{tabular}

Médias seguidas pela mesma letra minúscula na coluna não diferem estatisticamente em nível de $5 \%$ pelo teste de Tukey.

Médias seguidas pela mesma letra maiúscula na linha não diferem estatisticamente em nível de $5 \%$ pelo teste de Tukey. 
Conforme SHENOUDA (1980) a perda de umidade e de nutrientes hidrossolúveis, como é o caso do nitrogênio, ocorre pela desnaturação protéica da carne em baixas temperaturas de congelamento. A perda de água das moléculas de proteínas para a formação de cristais de gelo ocasiona a formação de agregados entre a miosina e a actina, ou a desnaturação de formas secundárias e terciárias de proteínas sarcoplasmáticas, resultando em desnaturação parcial a baixas temperaturas. Esse fenômeno tem como conseqüência a impossibilidade de reabsorção total da água durante o descongelamento, ocasionando a exsudação e a perda de umidade da carne por gotejamento.

\title{
4 CONCLUSÃO
}

Das três raças estudadas, a Piau evidenciou o menor índice de perda de massa da carne por exsudação (gotejamento) ao final dos períodos de descongelamento avaliados. As carnes das três raças apresentaram índices máximos de exsudação em 12 horas de avaliação, sendo a maior perda de massa demonstrada pela raça Landrace. As perdas nos teores de nitrogênio mostraram-se iguais para as três raças em todos os períodos estudados, porém aumentaram com maior tempo de descongelamento.

\begin{abstract}
MASS AND NITROGEN VARIATIONS IN SWINE MEAT AFTER THAWING

The objective of this work was to evaluate the physical-chemical quality of swine meat during thawing process, by determining mass and nitrogen variations by exudation. Samples of $300 \mathrm{~g}$ of pork loin of the races Landrace, Large White and Piau were frozen and later submitted to slow thaw. The evaluations of the samples of the three races were accomplished in three thawing times (6,12 and 24 hours). It was verified that the race Piau presented the smallest mass loss by exudation and the race Landrace presented the largest mass loss until 12 hours of thawing. There was no effect of the race on total nitrogen content contained in the exudates in the three appraised periods. However, there were significant increases in nitrogen concentration in the exudates with the increase of the thawing time of the three studied races.
\end{abstract}

KEY-WORDS: SWINE MEAT - FREEZING; WATER RETENTION.

\section{REFERÊNCIAS}

1 ARAÚJO, M.A. Química de alimentos: teoria e prática. Viçosa: Imprensa Universitária, 1995. 335 p. 
2 BANZATTO, D.A.; KRONKA, S.N. Experimentação agrícola. Jaboticabal: FUNEP, 1995. $247 \mathrm{p}$.

3 CECCHI, H.M. Fundamentos teóricos e práticos em análise de alimentos. Campinas: Editora da Unicamp, 1999.

4 CHEIFTEL, J.C.; CUQ, J.L.; LORIENT,D.. Proteínas alimentárias. Zaragoza: Acribia, 1986.

5 COLLIN, D. La carne y el frío. Madrid: Paraninfo, 1977. 199 p.

6 FENNEMA, O. R. Química de los alimentos. Zaragoza: Acríbia, 1993. 1095 p.

7 HONIKEL, K.O.; HAMM, R. Enfriado, congelado y descongelado: aspectos coloidoquímicos de la calidad de la carne. Fleischwirtsch, espanõl, v.1, p.4653, 1985.

8 JUDGE, M.D.; ABERLE, E.D.; FORREST, J.C.; HEDRICK, H.B.; MERKEL, R.A.. Principles of Meat Science. $2^{\text {nd }}$ ed. Dubuque: Kendall/Hunt Publishing, 1989. $351 \mathrm{p}$.

9 LEANDER, R. C. Comparison of structural changes in bovine longissimus and semitendinosus muscles during cooking. Journal of Food Science, Chicago, v. 45, n.3 p.173-178, 1980.

10 LOVATTO, P.A.; OLIVEIRA, V. Suinocultura geral. Santa Maria: UFSM, 1996.

11 PARDI, M.C.; SANTOS, I.F.; SOUZA, E.R.; PARDI, H.S. Ciência, higiene e tecnologia da carne. Goiânia: UFG, 1995. v. 1.

12 PELOSO, J.V. Qualidade da carne suína. Suinocultura Industrial, n.138, p.138139, 1999.

13 PIRES, I.S.C.; ROSADO, G.P.; AZEREDO, R.M.C. Proximate analysis, weight losses and tenderness of pork loin (longissimus dorsi) submitted to different freezing and thawing treatments. Rev. Nutr., v. 15, n. 2, p. 163-172, May/Aug. 2002.

14 SGARBIERI, V.C. Proteínas em alimentos protéicos. São Paulo: Varela, 1996.

15 SHENOUDA, S.Y.K. Theories of protein denaturation during frozen storage of fish flesh. Advances Food Research, New York, v.26, n.1, p.275-311, 1980.

16 WOOD, J. D.; HOLDER, J. S.; MAIN, D. C. J. Quality assurance schemes. Meat Science, v.49, p.191-203, 1998. 